\section{Diagnostic Accuracy of Frozen Section in Musculoskeletal Tumors}

\author{
SHAH FAHAD
}

MASOOD UMER

*Author affiliations can be found in the back matter of this article

\begin{abstract}
Introduction: Musculoskeletal tumors are rare group of disorders. To reach a diagnosis requires detailed medical history, physical examination, radiological investigations and histopathological correlation. Intra operative consultation plays an important role in the management of soft tissue tumors. However, there is a considerable lack of literature evaluating the diagnostic accuracy of frozen sections in musculoskeletal tumors. This study is aimed because no local data is available on the accuracy of frozen section in musculoskeletal tumors and frozen section allows intraoperative diagnosis.
\end{abstract}

Objective: To evaluate the diagnostic accuracy of intra-operative frozen sections for musculoskeletal tumors i.e, bone and soft tissue benign and malignant.

Study Design: Descriptive cross sectional study.

Setting: Section of Orthopaedic, Department of Surgery, The Aga Khan University Hospital.

Duration of Study: From 12 $12^{\text {th }}$ October 2018 to $5^{\text {th }}$ August to 2019.

Materials and Methods: A cross sectional descriptive study was designed to evaluate the Diagnostic accuracy of frozen section in musculoskeletal tumors at a tertiary care hospital, Karachi. All the patients meeting the inclusion criteria were enrolled in the study and sensitivity, specificity, PPV, NPV and diagnostic accuracy were calculated for frozen section keeping permanent section as gold standard.

Results: Of the total 88 patient 48 (54.54\%) were male and 40 (45.45\%) were female. Mean age was 30.75 years ( $5-80$ years). $63(71.59 \%)$ patients have bone tumors while 25(28.40\%) have soft tissue tumors. 50(56.81\%) patients have tumour involving lower extremity, 23(26.13\%) have upper extremity tumors and 15 (17.04\%) have tumour involving pelvis.

Overall sensitivity of frozen section for benign and malignant tumour of bone and soft tissue was $96.66 \%$, specificity was $100 \%$, positive predictive value $100 \%$, and negative predictive value $93.33 \%$ and accuracy was $97.72 \%$.

Conclusion: Frozen section serves as an invaluable and accurate tool in the intraoperative evaluation of musculoskeletal tumors. A diagnosis of musculoskeletal tumor by the frozen section method is highly reliable.

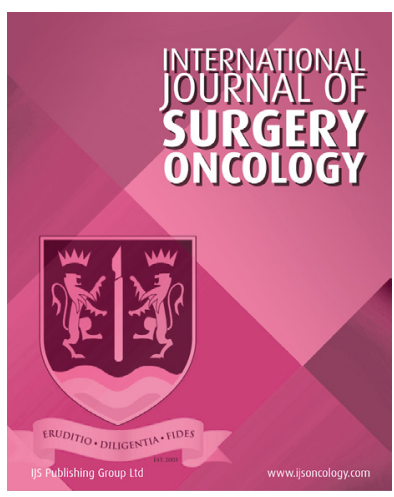

CROSS SECTIONAL STUDY

CORRESPONDING AUTHOR:

\section{Shah Fahad}

Aga Khan University Hospital, PK shahfahad_157@yahoo.com

\section{KEYWORDS:}

frozen section;

musculoskeletal tumor;

diagnostic accuracy;

histopathology; biopsy

TO CITE THIS ARTICLE: Fahad S, Umer M. Diagnostic Accuracy of Frozen Section in Musculoskeletal Tumors. International Journal of Surgery: Oncology. 2021; 6(1), pp. 10-17. DOI: https://doi. org/10.29337/ijsonco.25 


\section{INTRODUCTION}

Musculoskeletal tumors are rare group of disorder and must be kept in the differential diagnosis in patients with suspected symptoms. To reach a diagnosis requires detailed medical history, physical examination, radiologic investigations and histopathological correlation.

Management of musculoskeletal tumors of the extremities, especially the malignant ones, poses serious challenges to the clinicians. Etiology of musculoskeletal tumors is multifactorial. Predisposing factors include genetic mutations, trauma, infections, and irradiation. Some benign musculoskeletal tumors may progress to malignant tumors [1, 2]. An accurate record of the prevalence of musculoskeletal extremity tumors is difficult to obtain in Pakistan, because many of these patients may not present in the hospital, some that present in remote hospitals may not have proper diagnosis due to either lack of expertise or inadequate equipments, and even for those who have a proper diagnosis, proper record keeping may be a challenge. There is little doubt that diagnosing musculoskeletal tumors is far from straightforward [3].

There are few musculoskeletal lesions that can be diagnosed confidently based on imaging features alone. Even if a lesion is likely to bee a particular entity (e.g., metastasis in a patient with innumerable osseous lesions and a known primary malignancy), the implications for treatment are such that a definitive diagnosis is usually required. In these situations, biopsy of the suspicious lesion is warranted. Lesions that clinically and radiologically appear benign do not necessarily demand a biopsy. Some lesions that are benign radiologically appear aggressive or malignant histologically and potentially lead to overtreatment $[4,5]$.

The most common indications for biopsy of a bone or soft tissue lesion are to evaluate for neoplasm or infection. The consequences of an unsuccessful biopsy range from a delay in diagnosis to departure from the optimum treatment plan, including unnecessary amputation and worsening of prognosis and survival [6, 7].

Role of intra-operative frozen sections has been extensively studied for various cancers including gynecologic, prostate and head and neck malignancies [8, 9]. However, there is considerable lack of literature evaluating the diagnostic accuracy of frozen sections in musculoskeletal tumors.

The process of frozen section reporting includes gathering of radiological and clinical data, taking tissue intraoperatively by surgeon experienced in musculoskeletal tumour surgeries, rapid preparation of slides, staining and finally microscopic examination and analysis of the specimen [10]. An overall diagnostic accuracy of frozen sections has been shown to vary from 89 to $98 \%$ for various tissue types, however bone and soft tissue tumors still pose a major challenge owing to their rare incidence rate and therefore limited exposure of pathologists to these tumors [10].
During surgical resection of tumors, intra-operative frozen section consultation is useful for obtaining an adequate specimen for diagnosis as well as for evaluating tumour extent and margin status, hence guiding a surgeon to achieve disease free margins [10]. Thus, significantly reduces the chances of postoperative positive margins and primary recurrence of tumors $[9,11,12]$. However, results of frozen sections are not $100 \%$ accurate and false negative results may still lead to positive margins and tumour recurrence $[8,9]$. Sensitivity of frozen section is $88.2 \%$, specificity $94.7 \%$ and diagnostic accuracy $90.2 \%$ [13].

This study is aimed because no local data is available on the accuracy of frozen section in musculoskeletal tumors and frozen section allows intraoperative diagnosis which help to save patient's and surgeon's time compared to permanent section which takes two weeks time. If diagnostic accuracy is proved to be high by the study, frozen section can be used as useful diagnostic tool in future for the diagnosis of musculoskeletal tumors.

\section{OBJECTIVE}

To evaluate the diagnostic accuracy of intra-operative frozen sections for musculoskeletal tumors i.e, bone and soft tissue benign and malignant tumors keeping histopathology of permanent section as gold standard.

\section{OPERATIONAL DEFINITIONS}

\section{Frozen Section}

If the following characteristic features of tumors seen on frozen section, the results will be positive for benign tumors on frozen section; and if these features are not seen the result will be labeled as negative.

\section{Permanent Section}

If the following characteristic features of tumors seen on permanent section, the results will be positive for benign tumors on permanent section; and if these features are not seen the result will be labeled as negative.

True Positive: Positive result on both frozen section and permanent section.

True Negative: Negative result on both frozen section and permanent section.

False Positive: Positive on frozen section and negative on permanent section.

False Negative: Negative on frozen section and positive on permanent section.

Sensitivity: $\quad$ Proportion of true positives that are correctly identified by the test Formula: Number of true positive/ $\times 100$ 
Number of positive + number of false negative

Specificity:

Proportion of true negatives that are correctly identified by the test [14].

Formula:

Number of true negative/ $\times 100$

Number of true negative + number of false positive

Accuracy: $\quad$ True positive + true negative/ $\times 100$ True positive + true negative + false positive + false negative

Tumour type: $\quad$ Bone, soft tissue

Tumour location: Upper extremity, lower extremity, pelvis

\section{MATERIAL AND METHODS STUDY DESIGN}

Descriptive cross sectional study.

\section{SETTING}

Section of Orthopaedic, Department of Surgery, The Aga Khan University Hospital.

\section{DURATION OF STUDY}

From $12^{\text {th }}$ October 2018 to $5^{\text {th }}$ August to 2019.

\section{SAMPLING TECHNIQUE}

Non probability consecutive sampling whereby all patients fulfilling the inclusion criteria were recruited consecutively until the required sample size was reached.

\section{SAMPLE SELECTION}

Inclusion Criteria:

All patients of age under 5 to 80 years including male and female who will undergo surgical resection of bone and soft tissue tumors at The Aga Khan University Hospital, Karachi, in which frozen section specimens as well as permanent section specimen will be sent for evaluation.

\section{Exclusion Criteria:}

Patients with metastatic disease or those who undergo surgery with palliative intent.

\section{DATA COLLECTION PROCEDURE}

After ERC approval, patients meeting the inclusion criteria enrolled by using the Performa (Appendix-I).

All surgeries performed by experienced surgeons specialized in musculoskeletal tumour resection. Demographic characteristics recorded from hospital information management system (HIMS).
Frozen section and permanent sections were reviewed from the electronic database (HIMS). Final accuracy of frozen section was determined by comparing the results of frozen section with permanent section results.

Patient's confidentiality will be maintained and data will be stored in password protected computer with principle investigator.

\section{DATA ANALYSIS PROCEDURE}

Data was entered and analyzed into SPSS version-21. Descriptive statistics was calculated. Mean \pm SD was calculated for age of the patients. Frequency and percentage were calculated for gender, site, location, diagnosis of frozen section and histopathology respectively. Effect confounder like age, gender, site, location, site were addressed through stratification and post stratification and a $2 * 2$ table was constructed between frozen section and histopathology to calculate sensitivity, specificity, PPV, NPV and overall diagnostic accuracy.

\section{SAMPLE SIZE}

Sample size will be calculated by open resource diagnostics calculator:

Following were the mathematical calculations

Sensitivity $=88.2 \%[15]$

Specificity $=94.7 \%[15]$

Prevalence $=65.2 \%[15]$

Desired Precision $=7 \%$

Confidence interval $=95 \%$

The sample came out for sensitivity $=88 \&$ for specificity $=80$. So finally we will recruit larger sample size i.e. $n=88$ for sake of statistical significance.

\section{RESULTS}

Of the total 88 patient 48 (54.54\%) were male and 40(45.45\%) were female (Table 1). Mean age was 30.75 \pm 21.1 years (5-80 years). 63(71.59\%) patients have bone tumour while $25(28.40 \%)$ have soft tissue tumors (Table 1). 50(56.81\%) patients have tumors involving lower extremity, 23(26.13\%) have upper extremity tumors and $15(17.04 \%)$ have tumors involving pelvis (Table 1).

Overall sensitivity of frozen section for benign and malignant tumors of bone and soft tissue was $96.66 \%$, specificity was $100 \%$, positive predictive value $100 \%$, and negative predictive value $93.33 \%$ and accuracy was $97.72 \%$ (Table 2). The effect modifiers were also analyzed via regression which showed no significance for age, gender and side of tumors (Tables 3, 4 and 6). However significant positive diagnostic accuracy was found in tumors located in pelvis $(p=0.08)$ (Table 5). 


\begin{tabular}{|c|c|c|c|c|c|c|}
\hline \multicolumn{2}{|l|}{$\begin{array}{l}\text { GENDER } \\
\text { NO(\%AGE) }\end{array}$} & \multicolumn{2}{|c|}{$\begin{array}{l}\text { TUMOUR TISSUE TYPE } \\
\text { NO(\%AGE) }\end{array}$} & \multicolumn{3}{|l|}{$\begin{array}{l}\text { SITE OF TUMOUR } \\
\text { NO(\%AGE) }\end{array}$} \\
\hline $\begin{array}{l}\text { Male } \\
40(45.45 \%)\end{array}$ & $\begin{array}{l}\text { Female } \\
48(54.54 \%)\end{array}$ & $\begin{array}{l}\text { Soft tissue } \\
25(28.4 \%)\end{array}$ & $\begin{array}{l}\text { Bone } \\
63(71.6 \%)\end{array}$ & $\begin{array}{l}\text { Upper extremity } \\
23(26)\end{array}$ & $\begin{array}{l}\text { Lower Extremity } \\
50(57 \%)\end{array}$ & $\begin{array}{l}\text { Pelvis } \\
15(17 \%)\end{array}$ \\
\hline
\end{tabular}

Table 1 Gender, tissue type and site of tumour distribution.

\begin{tabular}{llll}
\hline \multirow{2}{*}{$\begin{array}{l}\text { FROZEN } \\
\text { SECTION }\end{array}$} & \multicolumn{2}{l}{ PERMANENT SECTION } & \multirow{2}{*}{ TOTAL } \\
\cline { 2 - 3 } & TUMOUR POSITIVE & TUMOUR NEGATIVE & \\
\hline Tumour positive & 58 & 0 & 58 \\
\hline Tumour negative & 2 & 28 & 30 \\
\hline Total & 60 & 28 & 88 \\
\hline
\end{tabular}

Table $22 * 2$ table between permanent section and frozen section.

Sensitivity: 96.66\%

Specificity: $100 \%$

Positive predictive value: $100 \%$

Negative predictive value: $93.333 \%$

Accuracy: $97.72 \%$

\begin{tabular}{|c|c|c|c|c|c|}
\hline \multirow[t]{2}{*}{ GENDER } & \multirow[t]{2}{*}{ FROZEN SECTION } & \multicolumn{2}{|c|}{ PERMANENT SECTION } & \multirow[t]{2}{*}{ TOTAL } & \multirow[t]{2}{*}{ P-VALUE } \\
\hline & & POSITIVE & NEGATIVE & & \\
\hline \multirow[t]{2}{*}{ Male } & positive & 29 & 0 & 29 & \multirow[t]{2}{*}{0.00} \\
\hline & negative & 2 & 17 & 19 & \\
\hline \multirow[t]{2}{*}{ Female } & positive & 29 & 0 & 29 & \multirow[t]{2}{*}{0.00} \\
\hline & negative & 0 & 11 & 11 & \\
\hline
\end{tabular}

Table 3 Co-relation of gender and histopathology via frozen section and permanent section.

\begin{tabular}{llllll}
\hline \multirow{2}{*}{ SITE } & FROZEN SECTION & \multicolumn{2}{c}{ PERMANENT SECTION } & \multirow{2}{*}{ TOTAL } & P-VALUE \\
\cline { 3 - 4 } & & POSITIVE & NEGATIVE & \\
\hline \multirow{2}{*}{ Right } & positive & 31 & 0 & 31 & \multirow{2}{*}{0.00} \\
\cline { 2 - 5 } & negative & 1 & 12 & 13 & \\
\hline \multirow{2}{*}{ Left } & positive & 27 & 0 & 27 & \multirow{2}{*}{0.00} \\
\cline { 2 - 5 } & negative & 1 & 16 & 17 & \\
\hline
\end{tabular}

Table 4 Corelation of side of limb involved and histopathology via frozen section and permanent section.

\begin{tabular}{|c|c|c|c|c|c|}
\hline \multirow[t]{2}{*}{ LOCATION } & \multirow[t]{2}{*}{ FROZEN SECTION } & \multicolumn{2}{|c|}{ PERMANENT SECTION } & \multirow[t]{2}{*}{ TOTAL } & \multirow[t]{2}{*}{ P-VALUE } \\
\hline & & POSITIVE & NEGATIVE & & \\
\hline \multirow[t]{2}{*}{ Upper limb } & Positive & 16 & 0 & 16 & \multirow[t]{2}{*}{0.00} \\
\hline & Negative & 0 & 12 & 12 & \\
\hline \multirow[t]{2}{*}{ Lower limb } & Positive & 34 & 0 & 34 & \multirow[t]{2}{*}{0.00} \\
\hline & Negatve & 2 & 13 & 15 & \\
\hline \multirow[t]{2}{*}{ Pelvis } & Positive & 8 & 0 & 8 & \multirow[t]{2}{*}{0.08} \\
\hline & Negative & 0 & 3 & 3 & \\
\hline
\end{tabular}

Table 5 Co-relation of Location and histopathology via frozen section and permanent section. 


\begin{tabular}{|c|c|c|c|c|c|}
\hline \multirow[t]{2}{*}{ AGE } & \multirow[t]{2}{*}{ FROZEN SECTION } & \multicolumn{2}{|c|}{ PERMANENT SECTION } & \multirow[t]{2}{*}{ TOTAL } & \multirow[t]{2}{*}{ P-VALUE } \\
\hline & & POSITIVE & NEGATIVE & & \\
\hline \multirow[t]{2}{*}{$<18$ years } & Positive & 20 & 0 & 20 & \multirow[t]{2}{*}{0.00} \\
\hline & Negative & 0 & 12 & 12 & \\
\hline \multirow[t]{2}{*}{$>18$ years } & Positive & 38 & 0 & 38 & \multirow[t]{2}{*}{0.00} \\
\hline & Negative & 2 & 16 & 18 & \\
\hline
\end{tabular}

Table 6 Co-relation of age and histopathology via frozen section and permanent section.

\section{DISCUSSION}

The interest of the orthopedic surgeon in the review of any musculoskeletal pathology is to identify the presence of malignancy or its absence, no matter how occult it may be and offers the patient the best possible treatment to cure, halt disease progression, or improve the quality of life. Musculoskeletal malignancy is one of major cause of death.

Histopathology plays an integral role in the multidisciplinary approach of treating patients with sarcoma, the accuracy of which has important therapeutic implications. Intraoperative frozen section consultation is particularly challenging. Indications for frozen section include making a diagnosis, evaluating margin status, determining tumor extent/spread, and obtaining an adequate sample for diagnosis. Few studies have been performed evaluating the role of frozen section in the diagnosis of musculoskeletal tumors. Among several larger studies, bone and soft tissue lesions constitute a small percentage of the total lesions studied.

Frozen section, being an intraoperative tool to help the surgeon make crucial decisions, should be reliable enough to avoid under- or over-diagnosis and subsequently inappropriate intervention. On table, a broad categorization into benign and malignant tumors is possible, thus helping the surgeon to decide on the extent of resection [16].

The overall accuracy was $97.72 \%$, sensitivity $96.66 \%$, specificity $100 \%$, positive predictive value $100 \%$ and negative predictive value was $93.33 \%$ in this study. The low false-positive rate observed in this study indicates the reliability of frozen section in diagnosing malignant tumors accurately. Bhaker et al. report sensitivity of $88.2 \%$, specificity of $94.7 \%$ in his study on 52 patients. Holaday and Assor [17] (reported 581 cases of bone and soft tissue frozen sections (5.8\% of total cases) with 96\% diagnostic accuracy. Shah et al. [18] reported that a specific diagnosis was made by frozen section in $85.9 \%$ cases with an overall diagnostic accuracy of $90.1 \%$ (82 of 91 cases). Histopathological diagnosis on routine paraffin section is used as the gold standard. A possibility in explaining why our results differ from prior investigations is that the technical expertise of our institution is robust and the volume of frozen section practice is large [19]. As a result, several tissue sections per specimen are examined within a relatively short time on a day-to-day basis, leading to progressive refinement of frozen section results. We do recognize that the reliability of the frozen section may be less in smaller practices. In our study the sensitivity and specificity for diagnosing bone tumors is $100 \%$. A study by Eréndira G.et al report 100\% sensitivity and $91 \%$ specificity in diagnosing bone tumors while report $100 \%$ sensitivity and specificity in ruling out malignancy [20].

Bone and soft tissue tumors present a greater challenge. Sarcomas are relatively rare compared to carcinomas. In most community hospital settings pathology services have limited exposure to bone and soft tissue tumors. Not all bone and soft tissue specimens are suitable for frozen section due to, for example, their bone and/or fatty components [10]. There were two discordant cases in our study. The first case was soft tissue tumour that was reported as lymphoid tissue on frozen section while paraffin stained sections reported as Hemangioma. Hemangioma in association with lymphoid tissue is a rare presentation of Hemangioma in which vascular lesion composed of vessels of varying caliber and lymphoid aggregate can be seen [21, 22]. The reason for this discordant is that in frozen section a small part of tissue is taken which is from the part of tumor containing lymphoid tissue only missing the component containing vessels. The other discordant case was a soft tissue tumour that was reported as mature fat cells on frozen section while paraffin stained section report it as atypical lipomatous tumour. Histologically atypical lipomatous tumour is formed by proliferation of relatively mature adipocytes consisting of mature fat cells and fibrous connective tissue. The immunohistochemical expression of p16, MDM2, and CDK4 is useful for distinguishing atypical lipomatous tumour from other lipomatous tumour [23]. For myxoid and adipocytic lesions, cytology was more useful than frozen section for diagnosis [10].

There seem to be no absolute contraindication to the use of FS diagnosis. Nonetheless, certain relative limitations. In some circumstances, potentially inappropriate ordering of FS does occur. Frozen section is sometimes unnecessary but not harmful to the patient, for example, a frozen section of a large tumour for which further surgery or treatment is not anticipated prior to a diagnosis based on permanent sections. Such cases 
may be avoided by means of discussion with the surgeon either during, or after the procedure. Such practices result in increased charges without any benefit to the patient. At other time, FS is not only unnecessary but also potentially harmful to the patient, for example, a FS on a small primary lesion that would be frozen in their entirety. Artifactual distortion or loss of tissue could hinder diagnosis [24].

Limitations of FS need to be taken into consideration when requesting for this procedure, in order to avoid grave mistakes that will be detrimental to the patient's management $[24,25]$. Poor sampling of tissue is a very obvious limitation for the pathologist since he has to interpret whatever the tissue sent by the surgeon. Poor selection of appropriate tissue after grossing tissue sample sent to the laboratory for FS is sometimes large and therefore the pathologist must use his discretion to sample the most representative tissue areas. This may greatly influence his interpretation. Sometimes the orientation of the tissue sent is not clear and communication with the surgeon in the OT is thus important. Sampling a large tumour is sometimes difficult. The surgeon must choose a viable area and avoid necrotic one. Recognizing areas of tissue reaction to tumour such as edema and fibrosis are also important as sampling of these areas sometimes leave the pathologist with no diagnostic material. Assessment of capsular or vascular invasion is very difficult in frozen section and subjected to sampling errors.

There is an acceptable limitation in the exact subtyping of soft tissue tumors, based on frozen section examination.

\section{LIMITATION}

The final histology was not independent of the frozen section diagnosis as the pathologists were not blinded is a limitation of the study.

\section{STRENGTH}

However, the strengths are that consecutive and all cases of frozen section were used, and a representative number of histological categories were available to make adequate statistical analysis. Moreover, all slides were examined and reported by senior histopathologist with special interest in bone and soft tissue tumors and in in the same institute.

\section{CONCLUSION}

Frozen section serves as an invaluable tool in the intraoperative evaluation of musculoskeletal tumors. It provides a quick, safe, and reliable intraoperative provisional tissue diagnosis especially to distinguish malignant from benign lesions. However, intraoperative diagnosis of benign soft tissue tumors by frozen section is preliminary and warrants confirmation by permanent section.

\section{APPENDIX-I}

Annexure

\section{Performa}

MR No:

Age (years):

Gender:

a) Male

b) Female

Type of tumor:

a) Bone

b) Soft tissue

Location of tumor:

Upper extremity

Lower extremity

Pelvis

\section{Frozen Section:}

Diagnosis:

Histopathology:

Diagnosis:

\section{COMPETING INTERESTS}

The authors have no competing interests to declare.

\section{AUTHOR AFFILIATIONS}

\section{Shah Fahad}

Aga Khan University Hospital, PK

\section{Masood Umer}

Aga Khan University Hospital, PK

\section{REFERENCES}

1. Coleman R. Metastatic bone disease: clinical features, pathophysiology and treatment strategies. Cancer Treat Rev. 2001; 27(3): 165-76. DOI: https://doi.org/10.1053/ ctrv.2000.0210

2. Iavarone A, Matthay KK, Steinkirchner TM, Israel MA. Germ-line and somatic p53 gene mutations in multifocal osteogenic sarcoma. Proceedings of the National Academy of Sciences. 1992; 89(9): 4207-9. DOI: https://doi. org/10.1073/pnas.89.9.4207

3. Schajowicz F. Tumorlike lesions. Tumors and tumorlike lesions of bone. Springer; 1994: 505-612. DOI: https://doi. org/10.1007/978-3-642-49954-8_10

4. Parikh J, Hyare H, Saifuddin A. The imaging features of post-traumatic myositis ossificans, with emphasis on 
MRI. Clin Radiol. 2002; 57(12): 1058-66. DOI: https://doi. org/10.1053/crad.2002.1120

5. Ragunanthan N, Sugavanam C. Pseudomalignant myositis ossificans mimicking osteosarcoma: a case report. Journal of Orthopaedic Surgery. 2006; 14(2): 219-21. DOI: https:// doi.org/10.1177/230949900601400224

6. Bickels J, Jelinek J, Shmookler B. Biopsy of musculoskeletal tumors. Operative Techniques in Orthopaedic Surgical Oncology; 2015.

7. Mankin H, Lange T, Spanier, SS. The hazards of biopsy in patients with malignant primary bone and soft-tissue tumors. J Bone and Joint Surg, 1121-7. DOI: https://doi. org/10.2106/00004623-198264080-00002

8. Bilodeau EA, Chiosea S. Oral squamous cell carcinoma with mandibular bone invasion: intraoperative evaluation of bone margins by routine frozen section. Head Neck Pathol. 2011; 5(3): 216-20. DOI: https://doi.org/10.1007/s12105011-0264-0

9. Fukamachi K, Ishida T, Usami S, Takeda M, Watanabe M, Sasano $\mathbf{H}$, et al. Total-circumference intraoperative frozen section analysis reduces margin-positive rate in breastconservation surgery. Jpn J Clin Oncol. 2010; 40(6): 513-20. DOI: https://doi.org/10.1093/jjco/hyq006

10. Bui MM, Smith P, Agresta SV, Cheong D, Letson GD. Practical issues of intraoperative frozen section diagnosis of bone and soft tissue lesions. Cancer Control. 2008; 15(1): 7-12. DOI: https://doi. org/10.1177/107327480801500102

11. Kumar S, Medeiros F, Dowdy SC, Keeney GL, BakkumGamez JN, Podratz KC, et al. A prospective assessment of the reliability of frozen section to direct intraoperative decision making in endometrial cancer. Gynecol Oncol. 2012; 127(3): 525-31. DOI: https://doi.org/10.1016/j. ygyno.2012.08.024

12. von Bodman C, Brock M, Roghmann F, Byers A, Löppenberg B, Braun $\mathbf{K}$, et al. Intraoperative frozen section of the prostate decreases positive margin rate while ensuring nerve sparing procedure during radical prostatectomy. J Urol. 2013; 190(2): 515-20. DOI: https:// doi.org/10.1016/j.juro.2013.02.011

13. Bhaker P, Mohan H, Handa U, Kumar S. Role of intraoperative pathology consultation in skeletal tumors and tumor-like lesions. Sarcoma. 2014. DOI: https://doi. org/10.1155/2014/902104

14. Altman DG, Bland JM. Diagnostic tests. 1: Sensitivity and specificity. BMJ: British Medical Journal. 1994; 308(6943): 1552. DOI: https://doi.org/10.1136/bmj.308.6943.1552
15. Bhaker P, Mohan H, Handa U, Kumar S. Role of intraoperative pathology consultation in skeletal tumors and tumor-like lesions. Sarcoma. 2014; 2014: 902104. DOI: https://doi.org/10.1155/2014/902104

16. Afroz N, Khan N, Hassan J, Huda M. Role of imprint cytology in the intraoperative diagnosis of pituitary adenomas. Diagn Cytopathol. 2011; 39(2): 138-40. DOI: https://doi.org/10.1002/dc.21394

17. Holaday W, Assor D. Ten thousand consecutive frozen sections: a retrospective study focusing on accuracy and quality control. Am J Clin Pathol. 1974; 61(6): 769-77. DOI: https://doi.org/10.1093/ajcp/61.6.769

18. Shah M, Garg V, Kapoor S, Dhaon B, Gondal R. Fine-needle aspiration cytology, frozen section, and open biopsy: relative significance in diagnosis of musculoskeletal tumors. J Surg Orthop Adv. 2003; 12(4): 203-7.

19. Ferreiro JA, Gisvold JJ, Bostwick DG. Accuracy of frozen-section diagnosis of mammographically directed breast biopsies. Results of 1,490 consecutive cases. Am J Surg Pathol. 1995; 19(11): 1267-71. DOI: https://doi. org/10.1097/00000478-199511000-00006

20. Estrada-Villaseñor EG, Cedillo ED, González LML, Martínez GR. Accuracy of intraoperative consultation for bone tumors: experience in an orthopedic hospital. J Orthop Sci. 2007; 12(2): 123-6. DOI: https://doi. org/10.1007/s00776-006-1096-8

21. Elgoweini M, Chetty R. Primary nodal hemangioma. Arch Pathol Lab Med. 2012; 136(1): 110-2. DOI: https://doi. org/10.5858/arpa.2010-0687-RS

22. Lakshmi SS, Prasad DD, Rao DS, Prasanthi C, Gangadharan V, Kumar CK. Primary hemangioma of a submental lymph node-a rare entity. International Journal of Medical Research \& Health Sciences. 2015; 4(2): 474-6. DOI: https://doi.org/10.5958/2319-5886.2015.00091.0

23. Thway K, Flora R, Shah C, Olmos D, Fisher C. Diagnostic utility of p16, CDK4, and MDM2 as an immunohistochemical panel in distinguishing well-differentiated and dedifferentiated liposarcomas from other adipocytic tumors. J Surg Pathol. 2012; 36(3): 462-9. DOI: https://doi. org/10.1097/PAS.0b013e3182417330

24. Jaafar H. Intra-operative frozen section consultation: concepts, applications and limitations. Malays J Med Sci. 2006; 13(1): 4-12.

25. Ackerman LV, Ramirez GA. The indications for and limitations of frozen section diagnosis; a review of 1269 consecutive frozen section diagnoses. Br J Surg. 1959; 46(198): 336-50. DOI: https://doi.org/10.1002/bjs.18004619806 
TO CITE THIS ARTICLE:

Fahad S, Umer M. Diagnostic Accuracy of Frozen Section in Musculoskeletal Tumors. International Journal of Surgery: Oncology. 2021; 6(1), pp. 10-17. DOI: https://doi.org/10.29337/ijsonco.25

Submitted: 23 January 2021 Accepted: 06 February 2021 Published: 23 March 2021

COPYRIGHT:

(c) 2021 The Author(s). This is an open-access article distributed under the terms of the Creative Commons Attribution 4.0 International License (CC-BY 4.0), which permits unrestricted use, distribution, and reproduction in any medium, provided the original author and source are credited. See http://creativecommons.org/licenses/by/4.0/.

IJS Oncology is a peer-reviewed open access journal published by IJS Publishing Group. 